\title{
ASSOCIATION BETWEEN LIPID LEVEL AND CHRONIC PERIODONTITIS IN PRODUCTIVE AGE AT COMPANY CLINIC IN JAKARTA, 2019
}

\author{
Bonita Putri Arinida, Adik Wibowo \\ Department of Health Policy and Administration, Faculty of Public Health, \\ Universitas Indonesia
}

\begin{abstract}
Background: Periodontitis affects at least $72 \%$ of Indonesian community according to Indonesian Basic Health Research (Riskesdas) in 2018. Periodontitis is considered as localized inflammation. However, the condition leads to systemic change. The recognition of systemic change was observed in lipid levels by several earlier studies. This study aimed to examine the association between lipid level and chronic periodontitis and healthy periodontal status in productive age.

Subjects and Method: This was a cross-sectional study conducted in a company clinic, in 2019. A total of 120 patients were selected consisting of 60 patients diagnosed with chronic periodontitis and the 60 patients with healthy periodontal status. The data of periodontitis patients were obtained from medical check-up. Data of lipid levels included total cholesterol, triglycerides, low-density lipoprotein (LDL) cholesterol, and high-density lipoprotein (HDL) cholesterol. The data were analyzed by a multiple linear regression.

Results: Patients with chronic periodontitis showed higher LDL cholesterol $(\mathrm{p}<0.001)$ and triglycerides $(\mathrm{p}=0.003)$ than patients with normal periodontal status. Total cholesterol was higher in patients with chronic periodontitis than healthy periodontal status $(\mathrm{p}<0.001)$. The difference in HDL cholesterol was statistically non-significant between patients with chronic periodontitis and healthy periodontal status $(\mathrm{p}=0.963)$.

Conclusion: Lipid level can be an indicator of periodontal disease and give more information to perform higher quality of examination. However, more studies are needed to strengthen the evidence for improving the medical check-up coverage.
\end{abstract}

Keywords: periodontitis, lipid level, inflammation, diagnoses

\section{Correspondence:}

Bonita Putri Arinida. Department of Health Policy and Administration, Faculty of Public Health, Universitas Indonesia, Depok West Java. Email: bonitaarinidadrg@gmail.com. Mobile: 081282269019.

\section{BACKGROUND}

Oral health has a direct and/or indirect impact on the conditions of general health. Since periodontal disease may relatable to other most worldwide non-communicable disease such as cardiovascular disease, diabetes and obesity, researches of periodontal disease were often conducted recently. As we have already known, cardiovascular disease as noncommunicable disease (NCD) which accounts most death in the world is also rank as first killer NCD in Indonesia (WHO, 2018; Ministry of Health, 2019).
The problem of periodontal disease is almost same with other non-communicable disease, painless at the first stage of disease development. The condition leads to more destructtive stage if the patients unaware to their dental health. In fact, patients with periodontal diseases are preventable with good oral hygiene. Unfortunately, according to Basic Health Research 2018 presented by Ministry of Health Republic of Indonesia, only $2.8 \%$ of Indonesians brushing their teeth correctly.

Chronic periodontitis is a condition characterized by the destruction of the 
junctional epithelium and connective tissue attachment of the tooth. The destruction also happened with bone destruction and formation of periodontal pockets. The disease progress slowly and the amount of bone loss tends to reflect the age of the patient over time (Scottish Dental, 2014).

In an early stage of periodontal disease, inflammation begins on gingiva which is known as gingivitis. The condition at this stage is still reversible. Gingiva is swollen and looks redness. Bleeding gum while brushing teeth is the common symptom at this stage. Most of the time, the condition doesn't become patient's concern. Thus, progress of alveolar destruction happens gradually. As destruction continues to alveolar bone, the condition is irreversible (Anjana \& Suresh, 2010)

Diseases of oral cavity have been seen separately from health of the rest of the body. However, recently efforts have been made to raise awareness that oral health is an integral part of overall health (Arigbede, et al., 2012). Periodontitis-induced changes immune cell function, through a mechanism involving proinflammatory cytokines, may cause metabolic dysregulation of lipid metabolism. Systemic exposure to infectious challenges such as two oral bacteria in periodontitis, Porphyromonas gingivalis and Streptococcus sanguis, can result in the release of inflamematory cytokines, such as IL-1 $\beta$ and Tumour Necrosis Factor alpha (TNF $-\alpha$ ) that alter fat metabolism and promote hyperlipidemia (Anjana \& Suresh, 2010; Paddmanabhan, 2013)

Nibali et al. (2007) evaluated 302 patients with severe periodontitis and 183 healthy controls to determine the correlation between periodontitis, inflammatory and metabolic biomarkers within case-control study. The study was conducted to observe leukocyte differential counts, high-density lipoprotein cholesterol (HDL), low-density lipoprotein cholesterol (LDL) and glucose. It is found that there was association between periodontitis and systemic inflammation. The data was mentioned useful for diagnosis of periodontitis in Caucasian patients by surveying inflammatory and metabolic biomarkers.

Cardiovascular disease, cause of $20 \%$ deaths in the world, is one of the most related to periodontal diseases. Data shows that periodontal disease relates to increasing of cardiovascular disease as high as $19 \%$. The increasing risk has been seen in productive age (Valensia, 2017). According to WHO (2001), productive age is at range 15-64 years old. This age range is in line with Indonesia's Ministry of Health (Ministry of Health, 2018).

As productive age increasing and become major population in Indonesia, they need more concerns related to its contribution on country's productivity on any aspect. Thus, almost all of companies regulate regular medical check-up to monitor their workforces. Aim of the study is to see the difference of lipid level between patients with chronic periodontitis and healthy gum conditions. Authors hope that it will help to improve quality and comprehensiveness of medical check-up.

SUBJECTS AND METHOD

\section{Study Design}

This was a cross-sectional study conducted in company clinic in 2019. It was performed by analyzing secondary data which were medical check-up results.

\section{Population and Sample}

Total of 176 subjects were selected and divided into two groups, based on periodontal status. First group was subjects with diagnosis of chronic periodontitis and the second one was subjects with healthy periodontal status. 
Lipid levels which become parameter in the study were total cholesterol, triglycerides, low-density lipoprotein (LDL) cholesterol and high-density lipoprotein (HDL) cholesterol.

The data were analyzed using STATA. Independent-t test was performed to analyze association between subjects and lipid levels which authors eager to know.

\section{RESULTS}

Data for the study were obtained from medical check-up results in one of company's cli- nic in Jakarta in 2019. Subjects are in a range of age $29-56$ years old as shown on table 1 . In medical check-up procedure, subjects were undergone several types of examinations, including physical, dental, laboratory and radiology examinations. Authors found 176 subjects in total to be observed for the study. Data has shown that majority of subjects who diagnosed by chronic periodontitis was male with $70.6 \%$ of total subjects in the study as seen on table 2 . We also made data distribution for lipid levels results in subjects

Table 1. Distribution of Subjects' Characteristics in the Study

\begin{tabular}{ccccc}
\hline & Min & Max & Mean \pm SD & Total \\
\hline Age & 29 & 56 & $44.72 \pm 8.128$ & 176 \\
\hline
\end{tabular}

Table 2. Distribution of Sex, Confounding Factors and Periodontal Status

\begin{tabular}{lcccccccc}
\hline \multirow{2}{*}{ Sex } & \multicolumn{2}{c}{ Smoking } & \multicolumn{2}{c}{ Diabetes } & \multicolumn{2}{c}{ CVD } & \multicolumn{2}{c}{ Periodontitis } \\
\cline { 2 - 9 } Male & No & Yes & No & Yes & No & Yes & No & Yes \\
Female & $64.4 \%$ & $100 \%$ & $69.1 \%$ & $78.6 \%$ & 68.8 & $100 \%$ & $66.7 \%$ & $70.6 \%$ \\
Total & $35.6 \%$ & $0 \%$ & $30.9 \%$ & $21.4 \%$ & $31.2 \%$ & $0 \%$ & $33.3 \%$ & $29.4 \%$ \\
& 149 & 27 & 162 & 14 & 170 & 6 & 33 & 143 \\
\hline
\end{tabular}

Table 3. Distribution of mean, standard deviation, minimum and maximum lipid levels

\begin{tabular}{lcccc}
\hline & Min & Max & Mean \pm SD & Total \\
\hline LDL-Cholesterol & 78 & 291 & $136.34 \pm 32.282$ & 176 \\
HDL-cholesterol & 60 & 91 & $73.73 \pm 7.616$ & 176 \\
Triglyceride & 103 & 323 & $144.53 \pm 29.769$ & 176 \\
Cholesterol Total & 142 & 372 & $212.05 \pm 36.017$ & 176 \\
\hline
\end{tabular}

Independent t-test was performed to analyze difference between lipid levels as dependent variable and chronic periodontitis. The results were shown on table 4 . There was significant difference LDL-Cholesterol level between subjects with chronic periodontitis and no gum disease subjects. However, there was no significant difference between group of healthy subjects and group of chronic periodontitis.
As seen in table 4, triglyceride level between two groups of subjects was significantly different. Similarly, subjects with chronic periodontitis were having higher total cholesterol level result in comparing to those without chronic periodontitis. Through bivariate analysis, there was found that no significant difference between cardiovascular disease, diabetes and smoking habits to lipid levels. 
Table 4. Bivariate Analysis between Lipid Levels and Groups

\begin{tabular}{|c|c|c|c|c|c|c|c|c|}
\hline \multirow{2}{*}{ Variable } & \multicolumn{2}{|l|}{$\begin{array}{l}\text { LDL- } \\
\text { Cholesterol }\end{array}$} & \multicolumn{2}{|c|}{ HDL-Cholesterol } & \multicolumn{2}{|l|}{ Triglyceride } & \multicolumn{2}{|c|}{ Total Cholesterol } \\
\hline & $95 \% \mathrm{CI}$ & $\mathrm{p}$ & $95 \% \mathrm{CI}$ & $\mathrm{p}$ & $95 \% \mathrm{CI}$ & $\mathrm{p}$ & $95 \% \mathrm{CI}$ & $\mathrm{p}$ \\
\hline \multicolumn{9}{|c|}{ Chronic periodontitis } \\
\hline Yes & 142 to 30.3 & 0.001 & 73.7 to 7.4 & 0.963 & 146.7 to 31.7 & 0.040 & 217.2 to 36.4 & 0.001 \\
\hline No & 111.6 to 28.9 & & 73.6 to 8.4 & & 134.9 to 16 & & 189.8 to 24.1 & \\
\hline \multicolumn{9}{|c|}{$\begin{array}{l}\text { Cardiovascular } \\
\text { Disease }\end{array}$} \\
\hline Yes & 134.5 to 29.7 & 0.888 & 77.8 to 8.6 & 0.18 & 137.2 to 6.8 & 0.054 & 193.5 to 45.2 & 0.349 \\
\hline No & 136.4 to 32.4 & & 73.6 to 7.6 & & 144.8 to 30.2 & & 212.7 to 35.6 & \\
\hline \multicolumn{9}{|l|}{ Diabetes } \\
\hline Yes & 137.1 to 31.9 & 0.929 & 71.4 to 9.1 & 0.337 & 149 to 33.4 & 0.607 & 215.7 to 28.4 & 0.63 \\
\hline No & 136.3 to 32.4 & & 73.9 to 7.5 & & 144.1 to 29.5 & & 211.7 to 36.6 & \\
\hline \multicolumn{9}{|c|}{ Smoking Habits } \\
\hline Yes & 134.8 to 26.3 & 0.762 & 74.8 to 8 & 0.429 & 146.4 to 31 & 0.733 & 211.8 to 34.6 & 0.967 \\
\hline No & 136.6 to 33.3 & & 73.5 to 7.5 & & 144 to 30 & & 212.1 to 36.4 & \\
\hline
\end{tabular}

Authors continued to multivariate analysis by considering confounding factor. We believed smoking habits, diabetes and cardiovascular disease were confounding factors in this study. The analysis was using multiple regressions linear. We made bivariate analysis for those confounding factors and only cardiovascular disease was found influencing number of HDL-cholesterol and triglycerides $(\mathrm{p}<0.25)$. However, we continued multivariate analysis to see correlation strength of independent variable to affect dependent. Authors included 2 independent variables only in triglycerides analysis related to bivariate results. Within cardiovascular disease and chronic periodontitis in analysis, it was found that $\mathrm{P}$ was 0.01 for both variables. However, cardiovascular disease had to be excluded ( $\mathrm{p}=0.522)$. After excluding cardiovascular disease from analysis, there was no significant change of chronic periodontitis coefficient and we got $\mathrm{p}=0.040$.

Table 5. Multivariate Analysis Result

\begin{tabular}{cccccccccc}
\hline \multirow{2}{*}{ Variable } & \multicolumn{2}{c}{ LDL-Cholesterol } & \multicolumn{2}{c}{ HDL-Cholesterol } & \multicolumn{2}{c}{ Triglyceride } & \multicolumn{2}{c}{ Total Cholesterol } \\
\cline { 2 - 27 } & R square & P & R square & P & R square & P & R square & P \\
\hline CP & 0.137 & 0.001 & 0.001 & 0.960 & 0.026 & 0.040 & 0.089 & - \\
\hline CVD & - & - & - & - & - & 0.522 & - & - \\
\hline
\end{tabular}

\section{DISCUSSION}

Investigation of association between lipid levels and periodontitis has been conducted since 1999. The more study performed, the stronger evidence that there is an association between periodontitis to lipid levels in blood and atherogenic, although there are also several evidences which prove that there is no association between these conditions (Saxlin, et al., 2008).
Several systemic conditions appear to be associated with patients who have periodontal disease (Paddmanabhan, 2013). These systemic conditions which are considered as predisposing factors and may contribute to evolution of periodontitis are diet, stress, obesity and some other underlying diseases such as diabetes, cardiovascular disease, osteoporosis and rheumatoid arthritis. Medications could also be inappropriate for the evo- 
lution of periodontal disease. Also, bad oral hygiene, tooth decay and tooth positioned incorrectly may also increase the risk of periodontal disease (Scottish Dental, 2014)

From the main finding of this study, data has shown that there were also association between LDL-Cholesterol, triglyceride, total cholesterol and chronic periodontitis. LDL-Cholesterol level is recommended below $100 \mathrm{mg} / \mathrm{dL}$. However, 100-129 mg/dL is still considered as tolerance threshold and more than $129 \mathrm{mg} / \mathrm{dL}$ has to be monitored as increasing of atheroma, cardiovascular disease and stroke risk factor.

In the study, it can be seen that subjects with chronic periodontitis significantly shows higher LDL-Cholesterol, above $100 \mathrm{mg} / \mathrm{dL}$. However, in both group of subjects show that both have good HDLcholesterol level, more than $60 \mathrm{mg} / \mathrm{dL}$, the recommendation threshold of HDL-cholesterol to help decrease vascular disease. Furthermore, triglyceride has been shown increasing in group with chronic periodontitis although has not been seen above recommendation.

The recommendation is ranged 150$199 \mathrm{mg} / \mathrm{dL}$ as high triglyceride level threshold and $200 \mathrm{mg} / \mathrm{dL}$ as high triglyceride level. Total cholesterol also shows significant difference and group with periodontitis have total cholesterol above the clinicians' recommendation. Healthy total cholesterol should be below $200 \mathrm{mg} / \mathrm{dL}$. Related to earlier systemic reviews study conducted by Nepomuceno et al (2017), 17 studies which were involving not less than 1.496 subjects showed higher total cholesterol in those with chronic periodontitis.

According to Lee et al. (2013), abnormalities in the serum lipid levels characterize dyslipidemia (DLP), which includes high levels of total cholesterol, triglycerides and LDL cholesterol, as well as decreased levels of HDL-cholesterol. A number of biologically plausible mechanisms have been suggested by the literature for results found in relationship to the four lipid parameters analyzed. Furthermore, several papers have investigated that association between periodontitis and lipid levels happen in a two-way relationship (Awartani \& Atassi, 2010; Nepomuceno, 2017).

In a result of this study, three or four lipid levels have shown significant change difference between subjects with chronic periodontitis and without chronic periodontitis. It shows linearity with other studies which have been conducted before. Inflammation that occurs in periodontal tissue can enter the systemic circulation, which later stimulates systemic effects. This association can be explained by the increased circulation of chemical mediators such as IL-1, TNF- $\alpha$, and thromboxane which are causing platelet aggregation, adhesion and formation of foam cells containing lipids, and cholesterol deposition in arteries.

Gram-negative bacteria that invade in the systemic circulation will stimulate the vascular response, including infiltration of inflammatory cells into the walls of blood vessels, degeneration of vascular lipid tissue, and intravascular coagulation (Valensia, 2017). Interestingly, Pires et al. (2014) also found that HDL-cholesterol did not differ in systemic change of lipid levels, especially in condition of dyslipidemia. HDL-cholesterol plays a role as removing LDL cholesterol from the walls of arteries. Low HDL-cholesterol happens due to decreased oxidation of other lipoproteins.

The systemic condition which can be resulted from chronic periodontitis has led encouragement to deepen study in larger area, moreover in related to cardiovascular disease. As one of the most cause of death in the world, Authors and clinicians always try to find new finding to decrease cause of disease or improve early finding of cardio- 
vascular disease. Recently, some studies have proven association between periodontal disease and cardiovascular disease which led more awareness to dental health as it can trigger other serious non-communicable diseases (Rosy, 2016; Kimak et al., 2015; Paddmanabhan, 2013).

Chronic periodontitis is one of asymptomatic non-communicable disease which condition can start locally but induce change in systemic condition. Related to result of the study, lipid levels can be both marker of continued periodontal condition and alarm of atherogenesis which can lead to other noncommunicable diseases.

However, deepen study should be conducted to strengthen the evidence. Moreover, many similar studies have been conducted but not take Indonesians as population. Studies which have been taken place in Indonesia were more about correlations of periodontitis to other NCDs. The condition should raise responsiveness to finding of disease itself and to lead early diagnosis of possibility other non-communicable disease.

\section{REFERENCES}

Anjana R, Suresh R (2010). Periodontal Infection-A Risk for Coronary Artery Disease.

Arigbede AO, Babatope O, Bamidele MK (2012). Periodontitis and Systemic Disease. PMC.

Awartani F, Atassi F (2010). Evaluation of Periodontal Status in Subjects with Hyperlipidemia. The Journal of Contemporary Dental Practice.

Kimak A, Strycharz-Dudziak M (2015) Lipids and Lipoproteins and Inflammatory Markers in Patients with Chronic Apical Periodontitis. Biomed Central

Lee JB, Yi HY, Bae KH (2013). The Association between Periodontitis and Dyslipidemia Based on the Fourth Korea National Health and Nutrition Examination
Survey. Journal of Clinical Periodontology

Ministry of Health (2018). Data dan Informasi Profil Kesehatan Indonesia. Pusat Data dan Informasi Kementerian Kesehatan.

Ministry of Health (2019) Hipertensi Penyakit Paling Banyak diidap Masyarakat. Retrieved from http://www.depkes.go.id/article/view/19051700002/hipertensipenyakit-paling-banyak-diidap-masyarakat.html.

Nepomuceno R, Pigossi SC, Finoti L (2017) Serum Lipid Levels in Patients with Periodontal Disease: A Meta-Analysis and Meta-Regression. Journal of Clinical Periodontology, 44(12).

Nibali D, Griffiths P, Suvan T (2007). Severe Periodontitis is associated with Systemic Inflammation and A Dysmetabolic Status: A Case-Control Study. Medline.

Paddmanabhan, P (2013). Is There Any Link Between Cardiovascular Disease, Obesity and Periodontal Disease? IOSR Journal of Dental and Medical Sciences (JDMS)

Pires JR, Dos Santos I, De Camargo L, Zuza EP, de Toledo BE, Monteiro SC (2014). Framingham Cardiovascular Risk In Patients With Obesity and Periodontitis. J Indian Soc Periodontol 18.

Riskesdas (2018). Laporan Nasional Riskesdas 2018. Badan Penelitian dan Pengembangan Kesehatan.

Saxlin T, Suominen-Taipale L, Kattainen A, Marniemi J, Knuuttila M, Ylostalo, P (2008) Association between serum lipid levels and periodontal infection. Journal of Clinical Periodontology.

Scottish Dental (2014). Prevention and Treat ment of Periodontal Diseases in Primary Care Dental Clinical Guidance. Scottish Dental Clinical Effectiveness Programme. Valensia R, Masulili SLC, Lessang R (2017) Association between Blood Cholesterol Level with Periodontal Status of Coronary 
Heart Disease Patients. AIP Conference

Proceedings. 1817(1).
WHO (2001). Age Standardization of Rates: A New WHO Standard. GPE Discussion Paper Series: No.31. 